\title{
Dredged Marine Raw Sediments Geotechnical Characterization for Their Reuse in Road Construction
}

\author{
Walid Maherzi $^{1, \mathrm{a}}$ and Farouk Ben Abdelghani ${ }^{2, \mathrm{~b}}$ \\ 1 Department of Civil Engineering, Ecole des mines de Douai, 941, rue Charles Bourseul, B.P. 838, 59508, \\ Douai, France \\ 2 Department of Civil Engineering, University of Tunis, Tunisia \\ E-mail: awalid.maherzi@mines-douai.fr, babdelghani_74@yahoo.com (Corresponding author)
}

\begin{abstract}
A large Research European Interreg IVA Program called "Sustainable Environmental Treatment and Reuse of Marine Sediment" is running in order to better understand the Channel sediment characteristics and to develop and promote sustainable management practices for marine sediments. A total of 13 sediments localized along the Manche channel were sampled and analyzed for SETARMS European project. A comprehensive series of laboratory tests were performed in order to characterize different sediments. This is a primordial step to class sampled sediments from a geotechnical point of view according to the French technical guide (GTR). This will be necessary to evaluate the potential use of treated sediments. Then to determine, with the French treatment guide GTS (soils treatment with lime and/or hydraulic binders) the appropriate formulation using hydraulic binders in order to improve sediments mechanical properties and allowing them to be reused in geotechnical applications, especially as a road material.

This paper presents and discusses results of physical and geotechnical characterization of different sediments sampled from different French ports. Geotechnical characterization results show that sediments have a great initial water content and are classified as fine and plastic materials with low to high organic matter content. Knowing that the variability of sediments characteristics is one of the limits to their reuse in geotechnical applications, the results will be presented and put in prospect towards this variability and the reuse of sediment as a subgrade layer.
\end{abstract}

Keywords: Marine sediments, dredged operation, geotechnical characterization, ability tests, SETARMS.

ENGINEERING JOURNAL Volume 18 Issue 4

Received 24 July 2013

Accepted 6 March 2014

Published 16 October 2014

Online at http:/ /www.engj.org/

DOI:10.4186/ej.2014.18.4.27 


\section{Introduction}

In order to receive modern ships with more important size and to avoid harbors entry siltation, significantly dredging operations are constantly required every year. These ports activities generate an important quantity of dredged marine sediments. In France, this quantity exceeds $45 \mathrm{Mm}^{3} /$ an. Immersion is usually adopted with respect to the national and international regulations.

Dredged operations are facing legal, economical, environmental, technical, scientific and social difficulties. Numerous research works were implemented to find new valorization solutions and beneficial uses for dredged sediment management plan, especially as reuse material on road construction $[1,2,3,4,5$, $6,7]$. Therefore, dredged sediment considered as fine material, their valorization will depend on application objective. Also, many research projects including many partners were initiated to find innovative solutions for dredged sediment management and valorization. We can name SETARMS European project (www.SETARMS.org) which aims to find a new and an innovative sediments valorization approach.

In France, more than 400 million tons of granular materials are consumed annually in civil engineering applications [8]. In order to ensure how best to treat and valorize dredged sediments in road construction (subgrade layer), the new material must respond to specifically criteria, especially mechanical performance, sustainability and environmental impact. Thus, a specific treatment for stabilized raw sediments will be necessary. Different treatment methodologies are selected depending on the type of each sediment in order to optimize their mechanical behavior. Thus, it will be necessary to explore the engineering properties for these raw and treated sediments.

Figure 1 shows our methodology approach for sediment treatment and valorization in road construction. Any valorization approach will need an experimental work to determine different sediment characteristics and properties. A well sediment characterization study will allows to evaluate the importance of sediment treatment, to determine the type of treatment product (lime, hydraulic binder) and to have a first idea on treatment additive quantity.

This study focused on raw sediments geotechnical characterization before their treatment and valorization on road construction. In this paper, geotechnical results for French sediments are presented and analyzed. These results are necessary for sediment classification according to the French road guide GTR [9] and to determine the type and percentage of treatment additives.

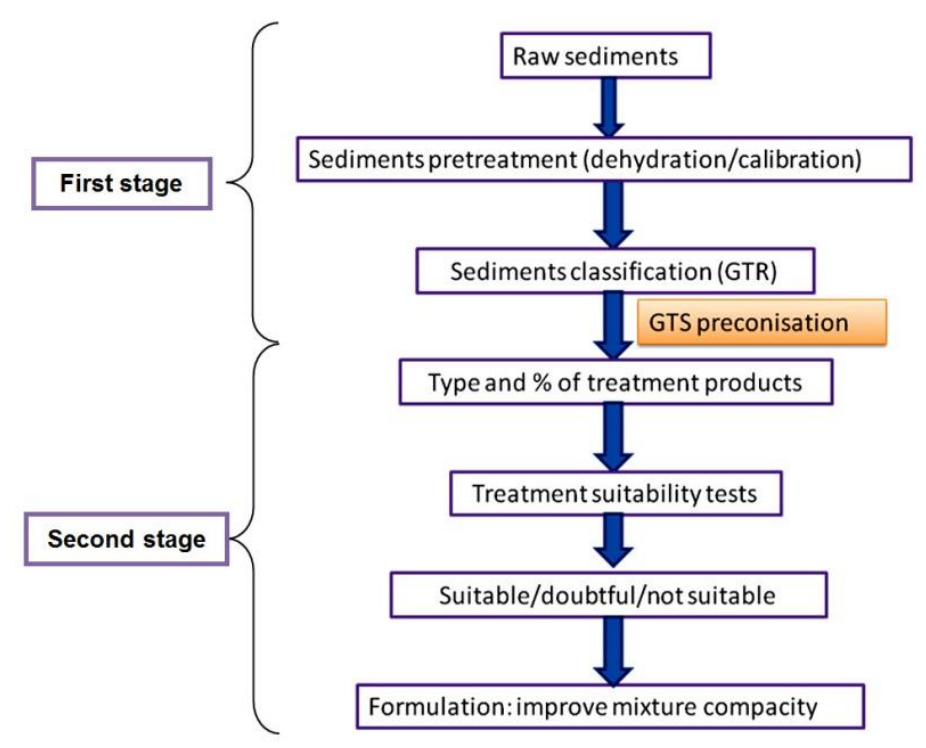

Fig. 1. Sediment valorization approach on road construction.

\section{Sampling Sites}

Different harbors were selected according to the European SETARMS project objective including eight French ports and five English ones. These harbors are localized along Chanel coast, one of the most used maritime ways in the world. Harbors location is reported on Fig. 2. 


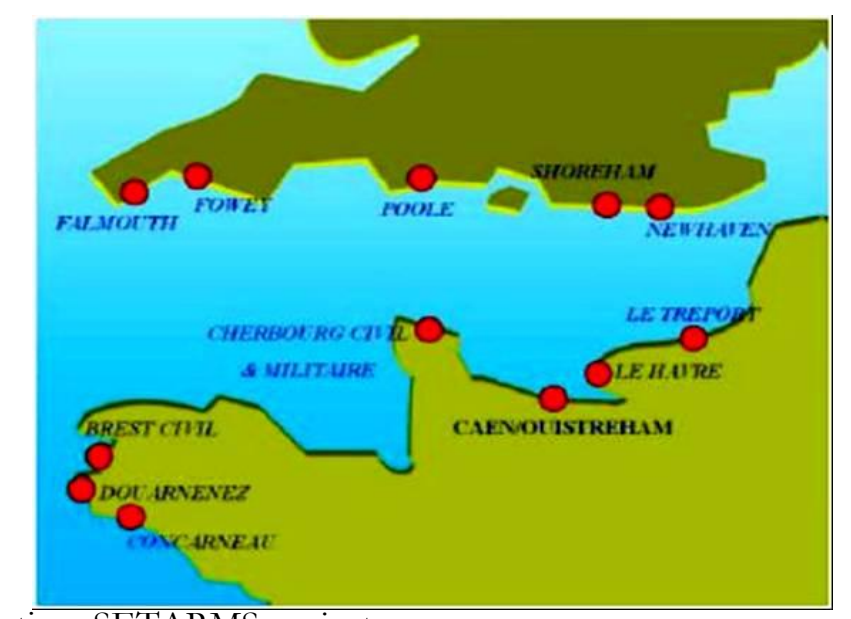

Fig. 2. Selected harbors location, SETARMS project.

Sediments site characteristics including sampling method, depths and sampling quantities are summarized in Table 1.

Table 1. Sediments sampling site characteristics.

\begin{tabular}{lccr}
\hline Sample & $\begin{array}{c}\text { Sampling } \\
\text { method }\end{array}$ & $\begin{array}{c}\text { Sampling } \\
\text { depth } \\
(\mathbf{m})\end{array}$ & $\begin{array}{r}\text { Sampling } \\
\text { quantities } \\
\text { (L) }\end{array}$ \\
\hline A001 & Clamshell & 7.0 & $9 \times 70 \mathrm{~L}$ \\
B001 & Diver & 8.0 & $10 \times 70 \mathrm{~L}$ \\
C001 & Diver & 4.0 & $8 \times 70 \mathrm{~L}$ \\
D001 & Dredged suction & 13.0 & $11 \times 55 \mathrm{~L}$ \\
E001 & Clamshell & 9.0 & $8 \times 70 \mathrm{~L}$ \\
F001 & Diver & 6.0 & $7 \times 70 \mathrm{~L}$ \\
G001 & Diver & 15.0 & $15 \times 69 \mathrm{~L}$ \\
\hline
\end{tabular}

In this paper, results for only French ports are presented and discussed. At date, all French ports are sampled. A total of 10 containers $(70 \mathrm{~L})$ of sediment were collected from each port. After sampling, contents of each container were combined and mixed to achieve a uniform composite sample. Due to their important initial water content, a sediment dehydration is necessary before starting experimental work. This is possible by natural decantation, use of geotextile or oven placed sediment (at a temperature of $40{ }^{\circ} \mathrm{C}$ ). Before any experimental analysis, sediment pretreatment should be conducted. This pretreatment procedure including grinding and calibrating (under $2 \mathrm{~mm}$ ), sediments homogenization, dehydration (natural or using geotextile), oven at $40{ }^{\circ} \mathrm{C}$ with decreasing water content to $0 \%$, sediments crushing and water content homogenization, and compacting in CBR moulds after 24 hours using dynamic compaction method.

Tests conducted in this study on raw sediments allow to determine their physical, geotechnical and mechanical characteristics and also to classify them according to the French technical guides, GTR [9] and GTS [10]. The GTR guide will provide a comparison of sediment properties to those of known soils. According to this classification and using the GTS guide recommendations, it will be possible to identify the type of treatment and quantities. Figure 3 shows different steps for sediment preparation for this physical and geotechnical characterization. 


\section{Results and Discussion}

\subsection{Physical Characteristics}

\subsubsection{Particle size analysis}

Particle size analysis (PSA) is an experimental investigation which allows to evaluate sediments relative grain size distribution. This distribution is used for sediment classification according to the French guide GTR [9]. Grain size analysis was performed using wet sieving for fraction greater than $80 \mu \mathrm{m}$ and by sedimentometry for elements smaller than $80 \mu \mathrm{m}$. Obtained results for the different analyzed sediments are shown in Table 2. Uniformity and curvature coefficients are also calculated and presented.

Table 2 shows that raw sediments are mostly silty-sand, exception of B001 which is clayey-sand. As it can be seen from Table 2, fine contents are very high with $100 \%$ value for B001. This indicates that analyzed sediments are very fine materials. Calculated uniformity coefficient values $\left(\mathrm{C}_{\mathrm{u}}\right)$ are greater than 2 indicating a spread distribution. Coefficient of curvature values $\left(\mathrm{C}_{c}\right)$ are less than 1 for E001 and G001 samples which indicates that these sediments may contain a large part of small elements. For the other samples, calculated $\mathrm{C}_{\mathrm{c}}$ values are greater than 3 which indicates the possibility of presence of coarse elements (in consequence, a lot of voids).
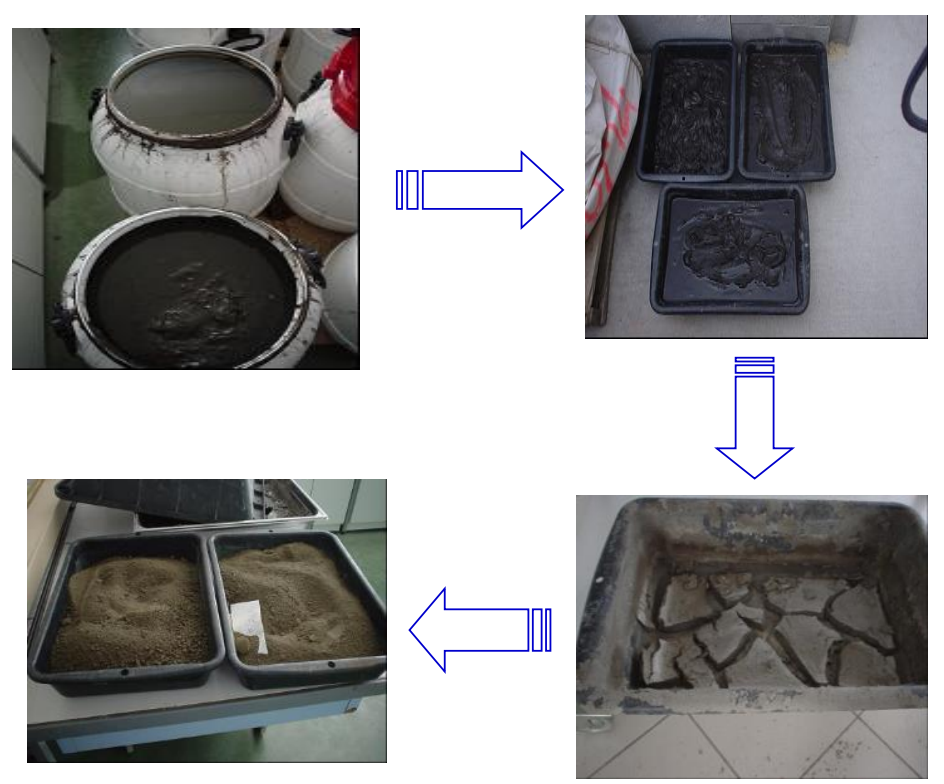

Fig. 3. Sediments preparation steps before their geotechnical characterization.

Table 2. Sediments particle size distribution.

\begin{tabular}{llllllll}
\hline Sample & A001 & B001 & C001 & D001 & E001 & F001 & G001 \\
\hline $\begin{array}{l}\%<2 \mu \mathrm{m} \\
(\text { Clay fraction) }\end{array}$ & 7.3 & 20.2 & 10.0 & 10.0 & 18.8 & 4.0 & 13.5 \\
$\begin{array}{l}2 \mu \mathrm{m}<\%<63 \mu \mathrm{m} \\
(\mathrm{silt} \text { fraction) }\end{array}$ & 38.0 & 67.4 & 35.7 & 40.5 & 71.1 & 24.0 & 73.1 \\
$\begin{array}{l}63 \mu \mathrm{m}>\% \\
(\text { Sand fraction) }\end{array}$ & 54.7 & 12.4 & 54.3 & 49.5 & 4.4 & 71.0 & 11.9 \\
$\begin{array}{l}\text { Fine content } \\
(\%<80 \mu \mathrm{m})\end{array}$ & 92.0 & 99.0 & 83.0 & 87 & 77.6 & 76.0 & 74.7 \\
$\begin{array}{l}\text { Uniformity coefficient } \\
\left(\mathrm{Cu}_{\mathrm{u}}\right)\end{array}$ & 2.2 & 30.0 & 1.0 & 4.1 & 82.78 & 9.0 & 47.6 \\
$\begin{array}{l}\text { Coefficient of } \\
\text { curvature }\left(\mathrm{C}_{\mathrm{c}}\right)\end{array}$ & 1.1 & 2.0 & 40 & 1.4 & 0.79 & 15.0 & 0.45 \\
\hline
\end{tabular}




\subsubsection{Water content}

Water content is a geotechnical parameter used to define the hydric state of raw sediment. For each sample, three values were determined at three different depths: top, medium and bottom. Previous works [3, 6] showed that, due to the high organic matter content of sediments, water content is performed at a temperature of $50^{\circ} \mathrm{C}$ (during 144 hours). This chosen value of temperature doesn't modify sediments structure. Obtained results are listed in Table 3. Minimum, maximum and mean values are also shown. According to the origin of sediments (marine site), initial water content values are very high, and can exceed $100 \%$, even $200 \%$. Table 3 shows that mean values vary between $70 \%$ (for B001 sample) and $235 \%$ (for F001). Water content values may be affected by sampling depth, sampling method (dredging technique) and sediments nature (water retention capacity, fine content and organic matter content). So, for sediments valorization and reuse in road construction, a dehydration is necessary to decrease the initial water content and to permit working with this material.

Table 3. Water content values for different sediments.

\begin{tabular}{lccc}
\hline Sample & $\begin{array}{c}\text { Minimum } \\
\mathbf{( \% )}\end{array}$ & $\begin{array}{c}\text { Maximum } \\
\mathbf{( \% )}\end{array}$ & $\begin{array}{c}\text { Mean value } \\
\mathbf{( \% )}\end{array}$ \\
\hline A001 & 115 & 116 & 115 \\
B001 & 66 & 73 & 70 \\
C001 & 168 & 245 & 230 \\
D001 & 93 & 104 & 99 \\
E001 & 184 & 194 & 188 \\
F001 & 233 & 238 & 235 \\
G001 & 79 & 109 & 97 \\
\hline
\end{tabular}

\subsubsection{Organic matter content}

Organic matter (O.M) presents some undesirable characteristics on road construction applications due to their swelling structure. For our study, organic matter was performed on $0 / 2 \mathrm{~mm}$ fraction by weight loose at a temperature of $450{ }^{\circ} \mathrm{C}$ during three hours. Obtained results are listed in Table 4. Each value represents a mean of five measurements. Results from Table 4 show that sediments have significant organic matter content with values varying from $5 \%$ (for B001) to $14 \%$ (for C001). Four samples have values between 3 and $10 \%$, and three others with values greater than $10 \%$, which indicates that sediments are organic to high organic materials. These values can have an important incidence on geotechnical and mechanical behavior of sediments. Organic matter can also have an impact on binder hydration during treatment stage. Also, these values will be necessary to establish a first classification of different sediments according to the French GTR guide.

Table 4. Organic matter content values for different raw sediments.

\begin{tabular}{lccc}
\hline Sample & $\begin{array}{c}\text { Minimum } \\
\mathbf{( \% )}\end{array}$ & $\begin{array}{c}\text { Maximum } \\
\mathbf{( \% )}\end{array}$ & $\begin{array}{c}\text { Mean value } \\
\mathbf{( \% )}\end{array}$ \\
\hline A001 & 10.2 & 10.4 & 10.3 \\
B001 & 4.8 & 4.9 & 4.8 \\
C001 & 13.9 & 14.3 & 14.1 \\
D001 & 7.6 & 7.7 & 7.6 \\
E001 & 10.6 & 10.9 & 10.7 \\
F001 & 11.1 & 11.7 & 11.4 \\
G001 & 5.3 & 5.6 & 5.4 \\
\hline
\end{tabular}

\subsubsection{Atterberg limits}

Atterberg limits are water content references related to sediment state change. These limits are the liquid limit (LL), which is the water content corresponding to state change from liquid to plastic; the plastic limit (PL) which is the water content representing change from plastic state to solid state; and the plasticity index (PI) which corresponds to the water content spread between the two previous limits for which sediment 
have a plastic behavior. PI is calculated by simple subtraction between LL and LP and is a measure of the argilosity.

Atterberg limits were measured on $0 / 4 \mathrm{~mm}$ fraction. Obtained results are listed in Table 5. The raw sediments exhibited a high liquid limits with values greater than $100 \%$. Table 5 shows that plasticity index values are high and exceed $20 \%$, except for B001 (PI = 15) and for C001 (PI = 20).

Usually, when water content increases, sediments evolve gradually from brittle material to plastic and then, to viscous liquid. This can influence their geotechnical and mechanical behavior. More PI values are important, more than sediment treatment with quicklime is imposed. Elevated PI values can influence on volume change with water content. Also, differences in obtained Atterberg limits reflect the anticipated variability in sediments encountered as a function of variable sampling locations.

Table 5. Atterberg limits of different raw sediments.

\begin{tabular}{lccccccc}
\hline Sample & A001 & B001 & C001 & D001 & E001 & F001 & G001 \\
\hline LL $(\%)$ & 100 & 36 & 70 & 94 & 119 & 130 & 57 \\
PL $(\%)$ & 38 & 21 & 50 & 50 & 53 & 60 & 34 \\
PI & 62 & 15 & 20 & 44 & 67 & 70 & 23 \\
A & 9.68 & 0.74 & 2.00 & 5.00 & 3.50 & 11.80 & 1.69 \\
\hline
\end{tabular}

Figure 4 shows the variation of organic matter content $(\mathrm{OM})$ and plasticity limit (PL) with the sample type (in the $\mathrm{x}$ axis). It can be seen that variation of these parameters is in the same way and that sediments with high organic matter induce high plasticity. This can have a significant influence on sediment response to treatment products and tests.

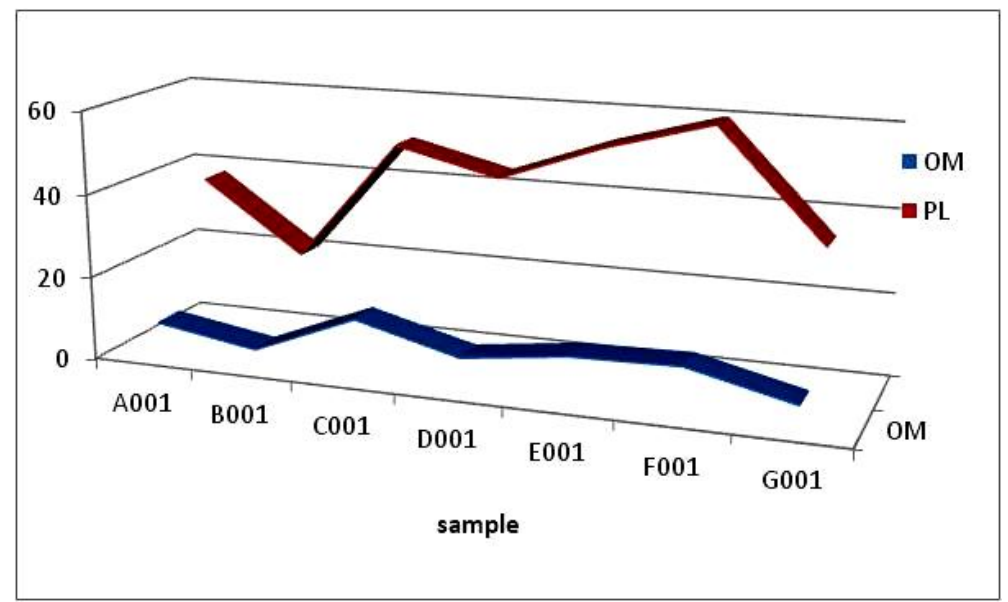

Fig. 4. Organic matter content and plasticity limit variations with samples.

\subsubsection{Methylene blue value and clay activity}

Sediment methylen blue value (VBS) is a measure of the clay activity. It consists of blue methylene quantity needed for saturation of suspension sediments in water. Since clay particles $(<2 \mu \mathrm{m})$ have the great capacity to absorb blue of methylene, this test can lead to a global estimation of clay activity contained in sediments. Obtained results are reported in Table 6.

Table 6. VBS and clay activity of different sediments.

\begin{tabular}{lccccccc}
\hline Identification & A001 & B001 & C001 & D001 & E001 & F001 & G001 \\
\hline VBS (g/100 g dry) & 3.3 & 1.2 & 2.2 & 2.3 & 1.4 & 2.9 & 1.2 \\
Clay activity (A) & 8.5 & 0.7 & 2.0 & 4.4 & - & 17.5 & - \\
(VBS/\% clay) & 8.5 & 0.74 & 2.0 & 4.4 & 3.6 & 17.5 & 1.7 \\
PI/\% clay & & & & & & & \\
\hline
\end{tabular}


VBS values are ranged between 1 and 3. High values are obtained for samples A001 and F001, whereas lowest value corresponds to B001 sediment. All VBS values are greater than $0.1 \mathrm{~g} / \mathrm{g}$ which means that sediments are sensitive to water.

For A001 and F001 samples, VBS is equals or greater than 3 showing that these untreated sediments are not reusable in road construction. Ratio between plasticity index (PI) and clay content is the clay activity (A) parameter and was also calculated. Except for B001, all clay activity values are greater than 1.25, which qualifies clays as active, i.e. represent swelling risk. These values should be correlated with clay mineralogy. For A001 and F001, clay activity values are very high related to their elevated PI values.

Argilosity variation with the sample type (in the $\mathrm{x}$ axis) expressed as clay activity and VBS values is plotted in "Fig. 5". This figure shows that variations of the VBS and clay activity are in concordance. This means that an increase or a decrease of VBS can be explained by an increase or decrease of clay activity, knowing that VBS is related to fine specific surface (not shown here).

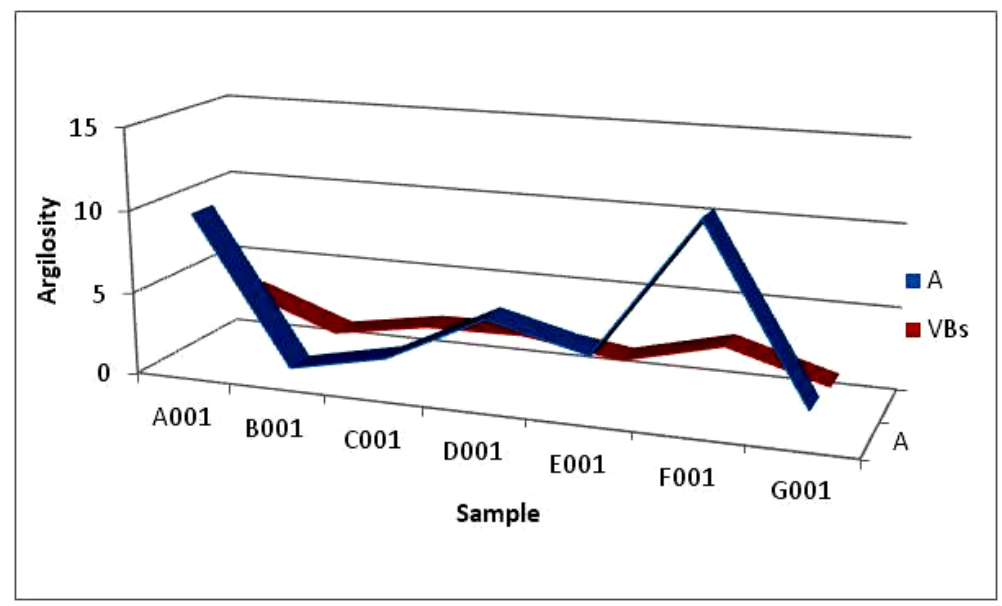

Fig. 5. Clay activity and VBS variations vs. sample type.

\subsection{Mechanical Characteristics}

\subsubsection{Compaction tests}

Sediment aptitude to compaction is defined by specific parameters which are the optimum water content, the maximum dry density and the immediate bearing index. These parameters were evaluated using normal Proctor test. This test consists to compact different sediments at various water content according to given process and energy. After compaction, immediate bearing index (IPI) was measured, which can indicates sediment ability to support site engines.

In Fig. 6, results for sample A001 are reported. Obtained results, the Proctor-IPI curve, represents variations of dry density and IPI (\%) with sediment water content. This curve shows an increasing of dry density with water content until reaching a maximum, than a decreasing. Also, immediate bearing index increases more rapidly with decreasing water content after Proctor optimum. Results show that raw sediments are sensitive to water. Consequently, to achieve proper compaction and filed work, dewatering of the sediment is a significant step for their treatment and future formulation for their reuse in road construction. 


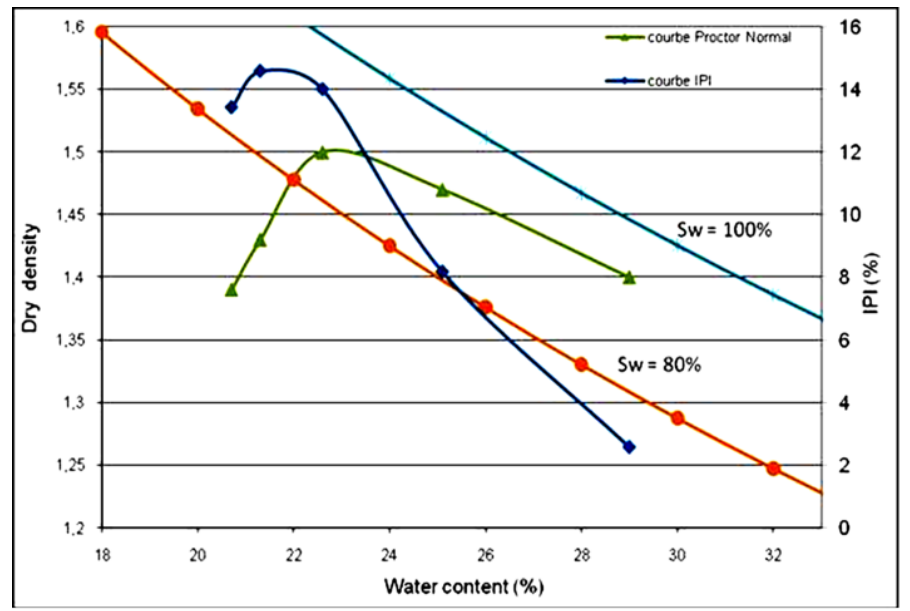

Fig. 6. Proctor-IPI curves for untreated sample A001.

Obtained values of maximum dry density and the corresponding optimum water content for different sediments are summarized in Table 6 . Immediate bearing index values are also indicated.

Overall, the compaction characteristics were relatively near. This may be attributed to the relatively high liquid limit observed for different sediments. The results (Table 7) suggest that increased optimum water content resulted in decreased maximum dry density. Figure 6 shows that IPI decrease with increasing water content is more pronounced after the optimum which can causes some difficulty for engine circulation on fieldwork.

Table 7. Normal Proctor parameters and immediate bearing index values of sediments.

\begin{tabular}{lccccccc}
\hline Identification & A001 & B001 & C001 & D001 & E001 & F001 & G001 \\
\hline $\mathrm{W}_{\text {opt }}$ & 21.0 & 19.0 & 30.0 & 19.0 & - & 21.0 & 21.5 \\
Qdopt $_{\text {IPI à } \mathrm{W}_{\text {opt }}(\%)}$ & 1.6 & 1.6 & 1.2 & 1.6 & - & 1.4 & 1.5 \\
\hline
\end{tabular}

From Table 6, all obtained IPI values at optimum water content are less than 20, a limit criteria for material to be used on road construction. Hence, a specific treatment will be necessary to improve sediments mechanical performance.

\subsection{Sediments Classification}

Physical and geotechnical sediment characteristics performed during this study were selected according to SETARMS main objective which consists to treat and valorize dredged sediments as a reuse material on road construction (subgrade layer material). Using obtained results and according to specific parameters shown in Table 7, it was possible to classify raw sediments using the the French GTR guide. GTR classification methodology is shown on Fig. 7. Obtained results are listed in Table 8. 


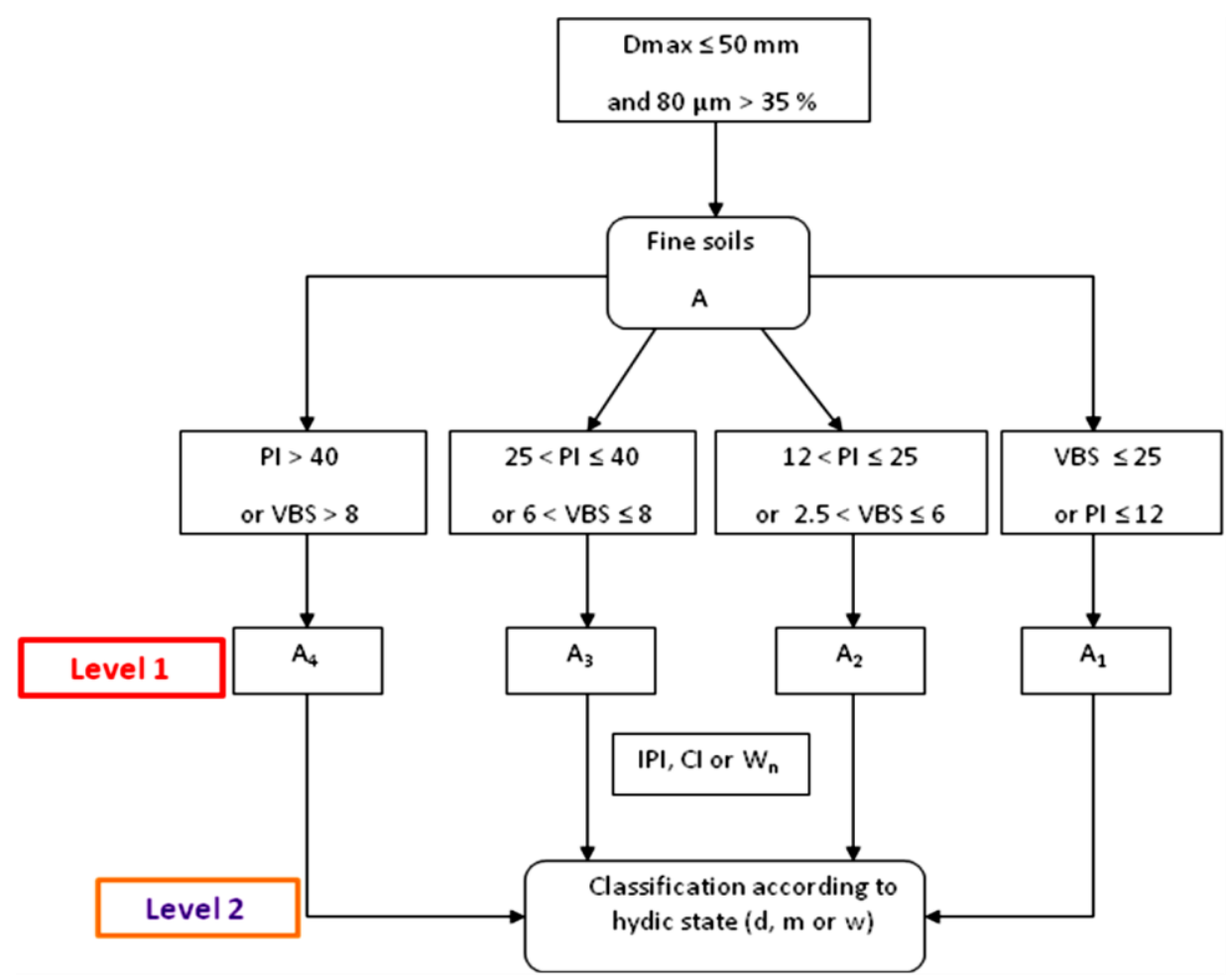

Fig. 7. Sediments classification methodology according to the French road Guide (GTR).

Table 8. Sediments classification according to the French guide GTR (1992).

\begin{tabular}{|c|c|c|c|c|c|c|c|}
\hline Classification parameter & A001 & B001 & C001 & D001 & E001 & F001 & G001 \\
\hline Organic matter (O.M) (\%) & $F_{11}$ & $\mathrm{~F}_{11}$ & $\mathrm{~F}_{12}$ & $F_{11}$ & $\mathrm{~F}_{12}$ & $\mathrm{~F}_{12}$ & $\mathrm{~F}_{11}$ \\
\hline $\begin{array}{l}\text { Maximum particle size (Dmax), } \%<80 \\
\mu \mathrm{m})\end{array}$ & A & A & A & A & $\mathrm{A}$ & A & A \\
\hline $\begin{array}{l}\text { Plasticity index (PI), sediment blue value } \\
\text { (VBS) }\end{array}$ & $\mathrm{A}_{2}$ & $A_{1}$ & $A_{1}$ & $A_{1}$ & $A_{1}$ & $\mathrm{~A}_{2}$ & $A_{1}$ \\
\hline $\begin{array}{l}\text { Immediate Bearing Index (IPI), } \\
\text { consistency index (CI) and natural water } \\
\text { content (Wn) }\end{array}$ & $\mathrm{A}_{2} \mathrm{~d}$ & $\mathrm{~A}_{1} \mathrm{~W}$ & $\mathrm{~A}_{1} \mathrm{~m}$ & $\mathrm{~A}_{1} \mathrm{~m}$ & - & $\mathrm{A}_{2} \mathrm{~m}$ & $\mathrm{~A}_{1} \mathrm{w}$ \\
\hline GTR classification & $\mathrm{A}_{2} \mathrm{dF}_{11}$ & $\mathrm{~A}_{1} \mathrm{wF}_{11}$ & $\mathrm{~A}_{1} \mathrm{mF}_{12}$ & $\mathrm{~A}_{1} \mathrm{mF}_{11}$ & - & $\mathrm{A}_{2} \mathrm{mF}_{12}$ & $\mathrm{~A}_{1} \mathrm{wF}_{11}$ \\
\hline
\end{tabular}

According to the French guide GTR and using organic matter values, all sediments belong to F class, the organic soils class. Three from studied sediments are classified as $F_{11}$ subclass for low organic soils and two to $F_{12}$ subclass defined for high organic materials. Based on From grain size distribution results, overall sediments are classified as fine soils, the class A, characterized by a maximum grain size (Dmax) less than $50 \mathrm{~mm}$ and fine percentage greater than $35 \%$. Subclass is then determined by clay activity (VBS) and sediment plastic index (PI). Thereby, two sediments belong to $A_{2}$ subclass and three to $A_{1}$.

Finally and according to the hydric state, it is possible to classify sediments based on their sensitivity to water. Thus, four sediments have a moderate hydric state (with $\mathrm{m}$ prefix), one sediment with a wet state (prefix w) and one last with dry hydric state (d prefix). The moderate state is the optimal because it minimizes fieldwork difficulties. 
From GTR suggestion and with obtained classification final results, untreated sediments are materials having water sensitivity with high plasticity. Using sediments in road construction as embankments materials can be allowed under specific conditions. But, to use them in roadways structure, additional tests are necessary for a better evaluation of their mechanical behavior.

The GTR/GTS classification involves treatment formulation (hydraulic binders proportions), compaction characteristics and limits of mechanical performance to achieve.

According to the GTS and with obtained final classification (see Table 8), sediment suitability tests must be conducted. The GTS preconise sediment treatment with $1 \%$ of quicklime and $7 \%$ of hydraulic binder (cement, class II). But, for economical aspect, we decided to use $6 \%$ of cement and lime fixation point test shows that $3 \%$ of quicklime will be necessary to reach a $\mathrm{pH}$ of 12.4 which corresponds to hydrates formation. Suitability tests consist of swelling monitoring and treated sediment strength evolution with time. Obtained results will show if different sediments will behavior similar or not to the chosen treatment. Results will be presented in future papers.

\section{Conclusion}

SETARMS is a large Research European Interreg IVA Program aiming to better understand the Channel sediment characteristics and to develop and promote sustainable management practices for marine sediments. It will produce a guideline in cooperation with ports, authorities, universities, scientific and industries around the Channel. It will provide also a durable network.

This paper presents a first treatment approach for sediment valorization and reuse in road construction as a sublayer material based on technical French guides, the GTR and GTS.

From the above results and discussions, dredged sediment experimental characterization is necessary for any sediment treatment and valorization on road construction. In this study, different laboratory tests were performed on different French sediments. Sampled sediments have initially a high water content which can exceed $200 \%$. This makes their dehydration necessary. Obtained results showed that sediments are fine material with high organic matter and clay activity. Also, they exhibit a certain sensibility to water.

Based on geotechnical characterization results and using standard guidelines for road construction, studied sediments were classified as fine materials (classes $A_{1}$ and $A_{2}$ ). According to GTS recommendations, a treatment formulation composed of $3 \%$ of quicklime and $6 \%$ of cement CEMII 32.5 may be applied. This formulation is needed to establish the suitability of different sediments for treatment and the conditions upon which the addition of quicklime and hydraulic binder may yield the treated dredged sediment suitable for subgrade layer application. Obtained results will be presented and discussed in other paper.

\section{Acknowledgement}

This research work is a part of the European Program SETARMS, cofounded by the European Regional Development Fund (Interreg IVA) and Conseil Régional Basse-Normandie. The authors would like to acknowledge the ERDF and CRBN for their financial support.

\section{References}

[1] M. Boutouil, "Treatment of dredged vase by solidification/stabilization by cement addition," M.S. thesis, Université du Havre, Le Havre, France, 1998.

[2] D. Colin, "Valorisation of fine dredged sediments in road construction," M.S. thesis, Université de Caen, Caen, France, 2003.

[3] V. Dubois, "Study of physico-mechanical behavior and environmental characterization of marine sediments," M.S. thesis, Université d'Artois, France, 2006.

[4] A. Semcha, "Dredged sediments valorisation: BTP Applications, case of Fergoug Dam," M.S. thesis, université de Reims, France, 2006.

[5] D. Levacher, D. Colin, C.A. Perroni, Z. Duan, L. Sun, "Recycling and valorization of fine dredged sediments for their reuse as road material," in IXèmes Journées Nationales Génie CivilGénie Côtier, Brest, France, 2006. 
[6] N. T. Thanh, "Valorization of marine and fluvial sediments in road construction," M.S. thesis, école des mines de Douai, France, 2009.

[7] L. Sannier, D. Levacher, and M. Jourdan, "Economic approch and validation of treatment methods by hydraulic binders of contaminated marine sediments," Rev. Para., vol. 2, pp. s2.1s2.15, 2009.

[8] R. Zentar, N. Abriak, and N. T. Tran, "Characterization and Environmental impact of dredged sediments in the North of France," Revue Para., vol. 2, pp. 4.1- 4.12.

[9] GTR, Realization of embakments and subgrade layers, Technical Guide, Fascicule II, Annexes techniques, SETRA-LCPC, 1992.

[10] GTS, Treatment of soils with lime and/or hydraulic binders, Application to the construction of pavement base layers, Technical Guide, SETRA-LCPC, 2000. 

